\title{
Comparative analysis on technologies between Chinese and American large-sized oil companies based on patentometrics
}

\author{
Zhao Qu*, Xiling Shen, Kun Ding \\ Institute of Science Studies and S and T Management, WISE Lab, Dalian University of Technology, Dalian 116024, China
}

\begin{abstract}
Patent information is critical and important object to reflect differences in technology capacity; the paper makes statistical analysis on structural elements of five large-sized oil companies from America and China as collected in Derwent Innovations Index, and compare technical similarities and differences between such companies' patents with visualization tools, by further research on academic classes, Derwent Class Code and co-occurrence of Manual Code. It is shown from the researches that Chinese enterprises is advantaged in growth in number of patents and cooperation rate, but their patents are characterized by poor influence, less relevance and connection between various disciplines, as well as relatively backward development of patented technology. Finally, according to current status of patents of Chinese and American oil companies, the paper proposes a series of recommendations and countermeasures for improvement in patents quality and future expansion in patented technology by Chinese oil companies.
\end{abstract}

Keywords: Comparative analysis, oil companies, patent statistics, patentmetrics

\section{INTRODUCTION}

Recently, the International Energy Agency and CBN Research Institute jointly release a report named as "World Energy Outlook 2013," which predicts after 2020, China will become the world's largest oil importing country, and by 2030 China will replace the American as the largest oil consumption country. China, India and other emerging economies are gradually becoming the main energy demanders world-wide. Meanwhile, such the demand promotes innovative development of oil-related technologies. Regarding development of conventional oil and gas exploration technology, China's oil companies

*Address for correspondence:

E-mail: qz_031@mail.dlut.edu.cnn

\begin{tabular}{|l|l|}
\hline \multicolumn{2}{|c|}{ Access this article online } \\
\hline Quick Response Code: & Website: \\
\cline { 1 - 2 } & www.jscires.org \\
\cline { 2 - 3 } & DOI: \\
\hline
\end{tabular}

keep are well-matched with international giants; however, China is still lagging behind in the field of exploitation and utilization of unconventional resource such as shale gas. In order to improve the international competitiveness and remain the existing advantages of China's oil companies, it is necessary to further study international giants' advanced technology, and shorten the gap with the developed countries in oil industry.

Patent is considered as knowledge carrier that integrates technical intelligence, business intelligence, and economic intelligence, and has become important objects for specifically studying scientific and technological development situation and innovation level. It is shown by data sourced from World Intellectual Property Organization: Patent information accounts for more than $90 \%$ of global output of $\mathrm{R}$ and $\mathrm{D}$ activities; ${ }^{[1]}$ therefore, patent literature has become a major source for obtaining emerging technologies. In recent years, Chinese scholars paid close attentions to macro examination on oil companies' competitiveness, ${ }^{[2,3]}$ but it is still a blank subject to make comparative analysis on technologies between Chinese and American large-sized oil companies from metric analysis on patents. 


\section{DATA AND METHODS}

The paper positions its target objects as 5 Chinese and American companies listed in World Oil Company top 25 as released in Forbes (2012), utilizes Assignee Code $\mathrm{AC}=(\mathrm{ESSO}-\mathrm{C}$ or CALI-C or CONO-C or SNPC-C or CNPC-C) as search limit conditions, thus to obtain 40,428 patents from 1963 to 2012 by Derwent Innovation Index (DII). It makes comprehensive analysis of current status of Chinese companies' patents, presenting similarities and differences in patent applications between five companies, which is conducted from views of the distribution of years, collaboration, $\mathrm{h}$ index, subject categories and DII Class Code. Furthermore, the author uses CiteSpace to make a DII Manual Code co-occurrence network for figuring out more information of five companies' patents by indicators of frequency and centrality. On the base of the conclusions above, the paper proposes correspondent countermeasures and the suggestion of improving the protection of patents and promoting technology innovation of Chinese oil industry.

\section{RESULTS AND DISCUSSION}

\section{Statistical Analysis on Structural Elements of Patent}

Oil industry is as an important part of the world economy, where patent activities are more active than ever, and it is an irresistible trend that various oil companies utilize patents to develop core competitiveness and further seize market opportunities. America is a proper example. Since the 1970s, American oil companies have accumulated a large number of patents and developed higher level utilization, protection and management capabilities of patents. Although Chinese companies launches patent protection on a late start if compared with American oil companies, they have gradually improved technological innovation capability and awareness of intellectual importance, also taken more and more measures to speed up patent portfolio since the "Patent Law" was implemented in 1985.

Table 1 shows the distribution of patent gross of American and Chinese oil companies as collected in DII from 1963 to 2012. Regarding the total number of patent applications, American companies take absolute dominance, and the number is up to 24,404 , and 1.5 times more than the total number of Chinese enterprises. Compared with top 25, it can draw a conclusion that business scale is positively correlated with a number of patents, namely well-funded company invest more in $\mathrm{R}$ and $\mathrm{D}$ activities with relatively powerful $\mathrm{R}$ and $\mathrm{D}$ capabilities. Chinese Oil Company ranks behind ConocoPhillips in comprehensive strength, but holds more patents than ConocoPhillips, which indicates that Chinese oil companies are trending to catch up American oil companies in technical development.

In addition, Table 2 shows distribution data of patent applications classified by years between China and the American oil companies.

The selected two Chinese oil companies applied for their first patents in 1980s, and then they applied for more and more patents exponentially; during only 2 years from 2011 to 2012 , the number of applications by two companies has reached 2 times of the number of applications during previous period of time. As for American oil companies, patent application is evenly distributed, and there is no significant fluctuation in each period, the overall trend is increasing in a steady and stable manner.

The paper analyses quantitatively patent external cooperation data Luan and Hou, 2008 ${ }^{[4]}$ from five Chinese and American oil companies from with cooperation rates. External cooperation rate is defined as a rate between the number of patents that an oil company jointly applies with other institutions or individuals and the total number of patents applied by such an oil company, which reflects the external relation network closeness and external cooperation frequency. In general, the higher the rate is, the more vigorous the company's scientific research is. Table 3 shows cooperation rates of five Chinese and American oil companies.

As table above listed, a company in the same country with more abundant fund and that ranks ahead shows a higher cooperation rate. ConocoPhillips' cooperation rate is slightly higher than Chevron's, but Chevron is

Table 1: Distribution of number of patent between Chinese and American oil companies

\begin{tabular}{llcccc}
\hline Enterprise rank & Enterprise name & Number of patents & Enterprise rank & Enterprise name & Number of patents \\
\hline 5 & Sinopec & 11,331 & 4 & ExxonMobil & 15,651 \\
23 & PetroChina & 4711 & 9 & Chevron & 5729 \\
& & & 21 & ConocoPhillips & 3024 \\
Total: 16,042 & & & Total: 24,404 & & \\
\hline
\end{tabular}


more advantaged in joint application quantity, its lower cooperation rate resulting from a large gross of patents that dilutes the proportion of independent applications. On the other hand, both Chinese oil companies, regardless of in number of joint patent applications, or in cooperation rate, are more advantaged than three American ones, which indicates oil companies in China has focused on patent cooperation, where various research and development companies play their advantages to make technical breakthrough, thus to avoid the waste arising from duplication of research and development, and to improve research performance significantly.

Furthermore, we classify cooperation into external and internal parts and show the details in Table 4.

Universities and research institutions account for a larger ratio of external joint applicants with Chinese oil companies, which indicates that the Chinese oil companies attach great importance to cooperation with research institutions. Such the cooperation on research activities between companies and academic institutions is helpful to promote knowledge flow and sharing, and to improve the level of technological innovation. In addition, the Chinese oil companies' patent applicants are generally three or less. But applicants of American oil companies mostly consists of five or more, and most of their partners are individuals, such as a patent application from Exxon Mobil

$\begin{aligned} & \text { Table 2: Annual distribution of patent applications } \\
& \text { between }\end{aligned}$
\begin{tabular}{lcc} 
Chinese and American oil companies \\
\hline Period & Chinese oil companies & American oil companies \\
\hline $1963-1970$ & 0 & 2198 \\
$1971-1975$ & 0 & 3027 \\
$1976-1980$ & 0 & 2688 \\
$1981-1985$ & 1 & 2779 \\
$1986-1990$ & 22 & 2185 \\
$1991-1995$ & 101 & 2207 \\
$1996-2000$ & 573 & 2038 \\
$2001-2005$ & 1045 & 2617 \\
$2006-2010$ & 4935 & 3164 \\
$2011-2012$ & 9330 & 1498 \\
\hline
\end{tabular}

jointly submitted by 22 applicants, including 19 individuals. It is shown that American oil companies are capable to fully utilize personal development advantage, and respect for freedom of scientific research, but they are in lack of regular interaction and cooperation with research institutes and universities, and perhaps this is one of main reasons why the number of patents slows down.

In 2005, Professor Jorge E. Hirsch proposed a new evaluation index $\mathrm{h}$ index, which was originally applied to the evaluation of academic achievements of scholars. ${ }^{[5]}$ As for patents h-index is defined as follows: Regarding a patent portfolio, if a patent among $\mathrm{h}$ patents is quoted by later patents at least $\mathrm{h}$ times, but the citation frequency of remaining patents is less than $\mathrm{h}$ times, such a patent portfolio's index is called as $\mathrm{h}^{\left[{ }^{[6]}\right.}$

As Table 5 stated, h-index and maximum citation frequency (the frequency of one patent that is mostly cited by others) of American companies are higher than Chinese ones. Exxon Mobil's h-index is 98, indicating that cited times of its 98 patents are not $<98$ times, and 23 patents are cited more than 200 times. PetroChina's h-index is only 4, and the maximum citation frequency is 14 times, indicating that the patent quality of American oil companies is much higher than Chinese enterprises', and American companies feature stronger patent influence, higher technical level, and more obvious contribution on technological progress and economic development.

Table 5 indicts that $\mathrm{h}$-index and maximum citation frequency are not significantly correlated with total number of patents, which means that larger gross of patent applications neither represents a higher h-index, nor a larger maximum citation frequency. It is shown from following analysis that in recent years, Chinese oil companies' patent application quantity has been obviously increasing, but if they only focus on quantity improvement, rather than patent quality improvement, they could not fundamentally enhance competitiveness in the oil sector.

Table 3: Cooperation rate of five Chinese and American oil companies

\begin{tabular}{|c|c|c|c|c|c|c|c|}
\hline $\begin{array}{l}\text { Company } \\
\text { name }\end{array}$ & $\begin{array}{c}\text { Independent } \\
\text { application quantity }\end{array}$ & $\begin{array}{c}\text { Joint application } \\
\text { quantity }\end{array}$ & $\begin{array}{c}\text { Cooperation } \\
\text { rate } \%\end{array}$ & $\begin{array}{l}\text { Company } \\
\text { name }\end{array}$ & $\begin{array}{c}\text { Independent } \\
\text { application quantity }\end{array}$ & $\begin{array}{c}\text { Joint application } \\
\text { quantity }\end{array}$ & $\begin{array}{c}\text { Cooperation } \\
\text { rate } \%\end{array}$ \\
\hline Sinopec & 2873 & 8458 & 74.64 & ExxonMobil & 10,045 & 5606 & 35.82 \\
\hline \multirow[t]{2}{*}{ PetroChina } & 2973 & 1738 & 36.89 & Chevron & 4574 & 1155 & 20.16 \\
\hline & & & & ConocoPhillips & 2403 & 621 & 20.54 \\
\hline $\begin{array}{l}\text { Chinese } \\
\text { companies }\end{array}$ & 5846 & 10,196 & 63.56 & $\begin{array}{l}\text { American } \\
\text { companies }\end{array}$ & 17,022 & 7382 & 30.25 \\
\hline
\end{tabular}


Table 4: Internal and external patent cooperation of Chinese and American oil companies

\begin{tabular}{lccclccc}
\hline $\begin{array}{l}\text { Company } \\
\text { name }\end{array}$ & $\begin{array}{c}\text { Internal joint } \\
\text { application }\end{array}$ & $\begin{array}{c}\text { External joint } \\
\text { application }\end{array}$ & $\begin{array}{c}\text { External } \\
\text { cooperation rate \% }\end{array}$ & $\begin{array}{l}\text { Company } \\
\text { name }\end{array}$ & $\begin{array}{c}\text { Internal joint } \\
\text { application }\end{array}$ & $\begin{array}{c}\text { External joint } \\
\text { application }\end{array}$ & $\begin{array}{c}\text { External } \\
\text { cooperation rate \% }\end{array}$ \\
\hline Sinopec & 4265 & 4193 & 37.00 & ExxonMobil & 1237 & 4369 & 27.92 \\
PetroChina & 280 & 1458 & 30.95 & Chevron & 538 & 617 & 10.77 \\
& & & & ConocoPhillips & 139 & 482 & 15.94 \\
Chinese & 4545 & 5651 & 35.23 & American & 1914 & 5468 & 22.41 \\
companies & & & & companies & & & \\
\hline
\end{tabular}

Table 5: Comparison on h-index of patents between American and Chinese oil companies

\begin{tabular}{|c|c|c|c|}
\hline Oil companies & Patent gros: & -index & Maximum citation frequency \\
\hline ExxonMobil & 15,651 & 98 & 1017 \\
\hline Chevron & 5729 & 55 & 192 \\
\hline ConocoPhillips & 3024 & 43 & 184 \\
\hline Sinopec & 11,331 & 21 & 56 \\
\hline PetroChina & 4711 & 4 & 14 \\
\hline
\end{tabular}

\section{Metric Analysis on Patents' Technology Contents}

Disciplinary categories are developed in accordance with SCI database disciplines classification standards, covering almost 250 subject categories from Acoustics to Zoology. There is only minor difference in top 10 advantaged disciplines among five companies: Chemical research, engineering science, fuel research are the strongest disciplines, and account for a higher proportion; in contrast, American companies are more advantaged than Chinese enterprises in the metallurgical sector; Chinese oil companies pay more attentions to applications of computer science in oil industry. In addition, although both countries' patents are mostly related to traditional disciplines in oil sector, American companies invest in research of last five disciplines in a more uniform manner, which indicates American companies conduct patent $\mathrm{R}$ and $\mathrm{D}$ activities in a more diversified and wider manner, and pay equal attentions to both traditional petroleum techniques and application petrochemical products. It is noteworthy by distribution of petroleum patent disciplines of Chinese enterprises, 613 and 262 patents are respectively related to water resources and materials science; as for American companies, 1284 and 807 patents are respectively related to transport and agriculture sectors, such the difference is closely related to the developing level and focus between two countries, and will be further analyzed in co-occurrence of DII Manual Code.

The frequency of five companies' patents are calculated by Derwent Class Code; the proportion of each class is arranged in descending order; then the top 10 classes of patents are comparatively analyzed as shown in Table 6. Although Derwent Class Code of both countries' patents are similar, there are differences in $\mathrm{R}$ and $\mathrm{D}$ investment and proportion of distribution technology. Chinese oil companies prefer to develop chemicals involved in mining and refining process, and American companies prefer application of petrochemical products. Tables 6 and 7 has stated that Chinese companies fall behind in patent applications, and their patent content are relatively easy, lack of innovation and application, reflecting that Chinese companies is weak in awareness of intellectual property protection, and showing technical development of China's oil industry lags behind developed countries.

Derwent Innovation Index Manual Code classifies patents from the perspective of technology applications, which is more specific than International Patent Class Codes and Derwent Class Code; and is capable to show patents' technological innovation features more effectively. ${ }^{[7]}$ Since China and American oil companies have obvious difference in time span of patent; the paper takes 3 years and 5 years as a period of span respectively to make co-occurrence analysis of manual code, as shown in Figures 1 and 2. Lines between nodes represent co-occurrence between manual codes, indirectly showing a correlation between corresponding technologies. Betweenness centrality represents degree of importance of co-occurrence network at a particular node, which reveals roles and influences of different technologies during development process of oil companies, and the horizontal axis gives appearance time of each node.

As shown in the figures above, five enterprise attach great importance to catalysts research, which is related to various chemical processes in production of petrochemical products, such as: Oxidation, hydrogenation, dehydrogenation and so on. The main techniques in American companies' patents also involves molecular sieve for gas refining and purifying. Generally, American oil companies' patents cover a wider range than Chinese companies, with closer relations between various technologies. The research and development of key technologies are more prominent, and have a comparative advantage in both quantity and technical content. 
Tables 8 and 9 list top 10 technologies ranked according to betweenness centrality in co-occurrence networks, by analysis in the corresponding period. Both countries are significantly different in time concentration in the same sector. Since 1973, American oil companies have been actively involved in catalyst research under chemical engineering research classification, and Chinese enterprises did the same after 15 years, such the lag also occurred in catalyst preparation, preparation of aliphatic hydrocarbons and other areas.

In the network of Chinese oil companies, the betweenness centrality of technologies related to compounds, which are produced with oil and catalyst as raw material, is higher, and correlated with other nodes. In addition to catalysts and compounds, American companies also make researches on petroleum preparation and application, which has been verified in Derwent Class Code. It is shown by Table 7 American companies applied oil patents in agriculture as earlier as 1963, patents related with fertilizers and agriculture appeared at that time. Although it is analyzed from disciplinary proportion China's oil companies have certain advantages in the field of computer science, American companies developed such technology 4 years earlier.

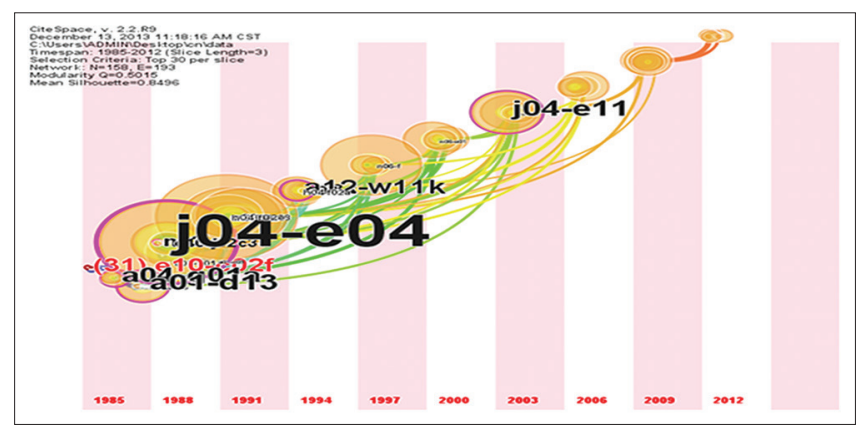

Figure 1: Co-occurrence of Derwent Innovation Index Manual Code of Chinese oil companies

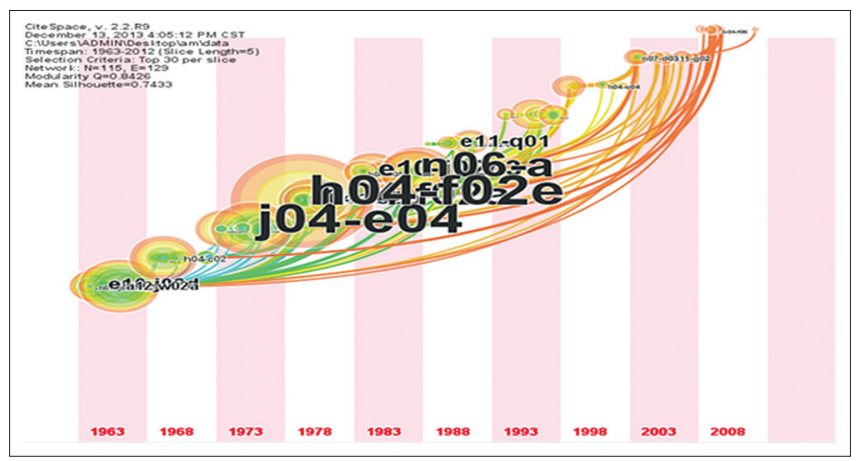

Figure 2: Co-occurrence of Derwent Innovation Index Manual Code of American oil companies

Table 6: Comparison on derwent class code (top 10) of Chinese and American oil companies

\begin{tabular}{|c|c|c|c|c|c|}
\hline Derwent class code (Chinese companies) & Quantity & Proportion \% & Derwent class code (american companies) & Quantity & Proportion \% \\
\hline H04 Petroleum processing & 3311 & 20.68 & H04 Petroleum processing & 5436 & 22.28 \\
\hline Q49 Mining & 2772 & 17.32 & H01 Obtaining crude oil and natural gas & 3194 & 13.09 \\
\hline J04 Chemical/physical processes/apparatus & 2518 & 15.73 & A17 Of unsubstituted aliphatic mono-olefins & 2852 & 11.69 \\
\hline H01 Obtaining crude oil and natural gas & 2342 & 14.63 & H07 Lubricants and lubrication & 2545 & 10.43 \\
\hline E17 Other aliphatics & 1769 & 11.05 & $\begin{array}{l}\text { A97 Miscellaneous goods not specified } \\
\text { elsewhere }\end{array}$ & 2337 & 9.58 \\
\hline $\begin{array}{l}\text { A97 Miscellaneous goods not specified } \\
\text { elsewhere }\end{array}$ & 1239 & 7.74 & $\begin{array}{l}\text { J04 Chemical/physical processes/ } \\
\text { apparatus }\end{array}$ & 2252 & 9.23 \\
\hline $\begin{array}{l}\text { S03 Scientific instrumentation photometry, } \\
\text { calorimetry }\end{array}$ & 1237 & 7.73 & E17 Other aliphatics & 2154 & 8.83 \\
\hline A41 Monomers and condensants & 1066 & 6.66 & H06 Gaseous and liquid fuels & 1858 & 7.62 \\
\hline E14 Aromatics & 875 & 5.47 & Q49 Mining & 1728 & 7.08 \\
\hline A17 Of unsubstituted aliphatic mono-olefins & 835 & 5.22 & E19 Other organic compounds general & 1474 & 6.04 \\
\hline
\end{tabular}

Table 7: Distribution of patent disciplinary category (top 10) of Chinese and American oil companies

\begin{tabular}{|c|c|c|c|c|c|}
\hline Disciplinary category (American companies) & Quantity & Proportion \% & Disciplinary category (Chinese companies) & Quantity & Proportion $\%$ \\
\hline Chemistry & 21,504 & 88.15 & Chemistry & 12,688 & 79.28 \\
\hline Engineering & 18,097 & 74.19 & Engineering & 12,438 & 77.72 \\
\hline Energy and fuels & 14,018 & 57.47 & Energy and fuels & 6482 & 40.50 \\
\hline Polymer science & 8577 & 35.16 & Polymer science & 4707 & 29.41 \\
\hline Instruments and instrumentation & 5223 & 21.41 & Instruments and instrumentation & 3870 & 24.18 \\
\hline Mining and mineral processing & 1728 & 7.08 & Mining and mineral processing & 2750 & 17.18 \\
\hline Transportation & 1284 & 5.26 & Water resources & 613 & 3.83 \\
\hline Metallurgy and metallurgical engineering & 906 & 3.71 & Computer science & 592 & 3.70 \\
\hline Computer science & 884 & 3.62 & Metallurgy and metallurgical engineering & 396 & 2.47 \\
\hline Agriculture & 807 & 3.31 & Materials science & 262 & 1.64 \\
\hline
\end{tabular}


Table 8: Annual distribution of betweenness centrality in derwent manual code of Chinese oil companies' patents (top 10)

\begin{tabular}{|c|c|c|c|}
\hline DII manual code & Technical contents & Betweenness centrality & Year \\
\hline j04-e04 & Catalysts & 0.37 & 1988 \\
\hline a01-d13 & Aliphatic hydrocarbons monoolefinic monomers & 0.17 & 1987 \\
\hline j04-e11 & Catalyst production & 0.17 & 2003 \\
\hline a04-g01a & Polymers from unsubstituted aliphatic monoolefinic monomers production & 0.16 & 1986 \\
\hline a12-w11k & Catalysts and supports & 0.15 & 1994 \\
\hline $\mathrm{n} 02-\mathrm{c}$ & Nickel-element, (HYDR) oxide, inorganic salt, carboxylate catalyst & 0.11 & 1988 \\
\hline n03-f & ZN, CD, Hg-element, (HYDR) oxide, inorganic salt, carboxylate catalyst & 0.1 & 1994 \\
\hline n03-e & MN, TC, Re-element, (HYDR) oxide, inorganic salt, carboxylate catalyst & 0.1 & 1994 \\
\hline e10-j02c3 & Aliphatic olefinic hydrocarbons-other production methods & 0.09 & 1988 \\
\hline h04-f02e & Preparation/composition of catalysts for other petroleum processes & 0.07 & 1991 \\
\hline
\end{tabular}

DII=Derwent innovation index

Table 9: Annual distribution of betweenness centrality in Derwent manual code of American oil companies' patents (top 10)

\begin{tabular}{llrr}
\hline DII manual code & Technical contents & Betweenness centrality & Year \\
\hline j04-e04 & Catalysts & 0.1 & 1973 \\
h04-f02e & Preparation/composition of catalysts for other petroleum processes & 0.1 & 1978 \\
n06-a & Molecular sieve; zeolite containing AL with no other metal than alkali & 0.08 & 1983 \\
h04-f02a & Preparation/composition of catalysts for petroleum treating & 0.07 & 0.05 \\
e10-j02c3 & Aliphatic olefinic hydrocarbons-other production methods & 0.04 \\
e10-j02d & Aliphatic saturated hydrocarbons & 0.04 & 1978 \\
h04-f02b & Preparation/composition of catalysts for petroleum cracking & 0.04 \\
e11-q01 & Eparation, extraction, recovery, purification-processes, apparatus & 0.03 \\
a12-w02a & Polymeric additives for lubricants and functional fluids & 1963 \\
h04-a01 & Petroleum processing-sweetening & 1978 \\
\hline
\end{tabular}

DII $=$ Derwent innovation index

Although China's oil companies lag behind in patented technology development to a certain degree, but in recent years, China's petrochemical companies represented by PetroChina and Sinopec are gradually growing up under an optimistic trend, which is closely related with increasing governmental support, improvement in corporate $\mathrm{R}$ and $\mathrm{D}$ strength and further cooperation with foreign oil giants. Chinese oil companies are not only catching up foreign companies in the number of patents, and also exploring wider, more innovative and more environmentally friendly technical themes.

\section{CONCLUSIONS}

Various countries worldwide are facing oil and energy challenges and competing more intensely. Asia-Pacific developing countries and region, such as China and India, are demanding more and more energy sharply, and their energy demand account for $40 \%$ of global demand increments, as well as $70 \%$ of in developing countries' demand increments. Patent literature is used as a major source for obtaining latest technology, and utilized as a powerful tool in compassion on technical differences between Chinese and American oil companies.

It is concluded through comparative study that Sinopec and Chine Petro, China's two oil giants, applied for related patents on a late start, resulting in their patent gross far behind American oil companies', and their h-index is also generally lower than the American oil companies', which indicates their patents' external influence is limited. Meanwhile, the patents contains less disciplines, patented content is too concentrated, patented technology is more simple, in lack of practicality and innovation, and they lag behind in development of key technologies. However, Chinese two oil companies maintain a rapid growth momentum in patent applications, and it is just around the corner that they will catch up with American companies in patent gross depending on current exponential growth rate. Chinese oil companies attach more impotence to cooperation and exchanges with research institutes and universities, as well as internal subsidiaries, and conduct extensive joint patent applications; such the strategy is helpful to comprehensively improve quality of patents and expand patent content within a short time. 
It is recommended Chinese oil companies should not only remain a rapid growth rate in number of patents, and also make efforts to improve quality of patents, thus to create simultaneous growth in both quality and quantity, and avoid wasting resources, and realize intrinsic value of patents. In addition, it is necessary to pay close attentions to change trends in technical content of patent applications by foreign oil companies, and speed up patent application process in key technology areas, thus to seize the market opportunities. Under the background of new energy era, it is also recommended to further apply for patents related to new energy technologies such as coal gasification, cellulosic ethanol, and algae biofuels, thus to expand the patent content and technology, and create new opportunity for development of Chinese oil companies. Governmental departments should further perform their functions to increase financial support for patent research, and improve relevant laws and regulations, thus to provide favorable external environment for patent research and development of Chinese oil companies, and promote stable, orderly and sound development of oil companies' patented technology.

\section{ACKNOWLEDGMENT}

The abstract of the present paper was accepted as oral presentation at the " $10^{\text {th }}$ International Conference on Webometrics, Informetrics, and Scientometrics (WIS) and the $15^{\text {th }}$ COLLNET Meeting 2014" held from 3 to 5 September 2014, In Technocal University of Ilmenau, Germany. The author could not attend the conference and present the paper.

\section{REFERENCES}

1. Liu CY, Yang JC. Decoding patent information using patent maps. J Data Sci 2008;7:14-22.

2. Yang R. International comparison on competitiveness of Chinese oil industry. J Econ Rev 2004;1:52-7.

3. Yang GQ, Wu YY. International comparative study on competitiveness of global oil companies based on value chain. J World Econ Res 2013;5:10-6.

4. Luan CJ, Hou HY. Meric analysis and compassion on patent external cooperation of Chinese and foreign major companies, by taking digital information transmission technology as an example. J Sci Manage Res 2008;26:86-8.

5. Hirsch JE. An index to quantify an individual's scientific research output. Proc Natl Acad Sci U S A 2005 15;102:16569-72.

6. Guan JC, Gao X. Exploring the h-index at patent level. J Am Soc Inf Sci Technol 2009;60:35-40.

7. Gao JP, Ding K. Comparison on nanotechnology patent between Mainland and Taiwan and industrial development strategy. J Res Manag 2012;33:100-9.

How to cite this article: Qu Z, Shen X, Ding K. Comparative analysis
on technologies between Chinese and American large-sized oil
companies based on patentometrics. J Sci Res 2014;3:68-74.
Source of Support: Funded by Natural Science Foundation of
China, "analysis on evolution of SIPOD patent knowledge based on
Chinese text mining technology" (project number: 61272370), (starting
and ending dates: January 2013-December 2013); Special Fund for
Research Program of Doctoral Discipline Stations in Higher Colleges,
"researches on measurement system of patent knowledge and its
application based on SIPOD" (project number: 20110041110034),
(starting and ending dates: January 2012-December 2014), Conflict
of Interest: None declared

\section{"Quick Response Code" link for full text articles}

The journal issue has a unique new feature for reaching to the journal's website without typing a single letter. Each article on its first page has a "Quick Response Code". Using any mobile or other hand-held device with camera and GPRS/other internet source, one can reach to the full text of that particular article on the journal's website. Start a QR-code reading software (see list of free applications from http://tinyurl.com/ yzlh2tc) and point the camera to the QR-code printed in the journal. It will automatically take you to the HTML full text of that article. One can also use a desktop or laptop with web camera for similar functionality. See http://tinyurl.com/2bw7fn3 or http://tinyurl.com/3ysr3me for the free applications. 